Supplemental Information for:

\title{
Simultaneous Detection of Ozone and Nitrogen Dioxide by Oxygen Anion Chemical Ionization Mass Spectrometry: A Fast Time Response Sensor Suitable for Eddy Covariance Measurements
}

Gordon A. Novak, Michael P. Vermeuel, Timothy H. Bertram

Department of Chemistry, University of Wisconsin - Madison, Madison, WI, USA

Correspondence to: Timothy H. Bertram (timothy.bertram@wisc.edu) 


\begin{tabular}{lc}
\hline Component & Voltage (V) \\
\hline & 1.5 \\
\hline IMR Region (95 mbar) \\
\multicolumn{1}{c}{ CDC/ Short Segmented Quadrupole Region (2mbar) } \\
Lens Nozzle & -1.1 \\
SSQ Entrance Plate & -3.5 \\
SSQ Front & -4.2 \\
SSQ Back & -5.8 \\
Lens Skimmer & -5.7 \\
Skimmer & -3.9 \\
Big Segmented Quadrupole Region $\left(1.2 \times 10^{-3} \mathrm{mbar}\right)$ \\
BSQ Front \\
Skimmer 2
\end{tabular}

Table S1: Operational ion optic voltages and chamber pressures for the three front end chambers of the Ox-CIMS. Ion declustering strength is primarily determined by the voltage difference between the Skimmer and BSQ Front. The nomenclature of Brophy and Farmer. (2016) is used for ion optic component labelling. 


\begin{tabular}{l|cc}
\multicolumn{1}{l}{ Reagent Ion } & \multicolumn{1}{c}{$\begin{array}{c}\mathbf{O}_{2}^{-} \\
\left(\mathbf{k c a l ~ m o l}^{-1}\right)\end{array}$} & $\begin{array}{c}\mathbf{C O}_{3}^{-} \\
\left(\mathbf{k c a l ~ m o l}^{-1}\right)\end{array}$ \\
\hline $\mathrm{H}_{2} \mathrm{O}$ & -18.97 & -13.18 \\
$\mathrm{H}_{2} \mathrm{O}_{2}$ & -29.42 & -21.15 \\
$\mathrm{CH}_{3} \mathrm{OOH}$ & -25.00 & -7.92 \\
$\mathrm{HNO}_{3}$ & -26.76 & -24.10
\end{tabular}

Table S2: Calculated binding enthalpies in kcal mol ${ }^{-1}$ for $\mathrm{O}_{2}^{-}$and $\mathrm{CO}_{3}^{-}$reagent ions to water $\left(\mathrm{H}_{2} \mathrm{O}\right)$, hydrogen peroxide $\left(\mathrm{H}_{2} \mathrm{O}_{2}\right)$, methyl hydrogen peroxide $\left(\mathrm{CH}_{3} \mathrm{OOH}\right)$, and nitric acid $\left(\mathrm{HNO}_{3}\right)$ in kcal mol-1. Calculations were performed with the MP2/aug-cc-pvdz-PP theory and basis set. 


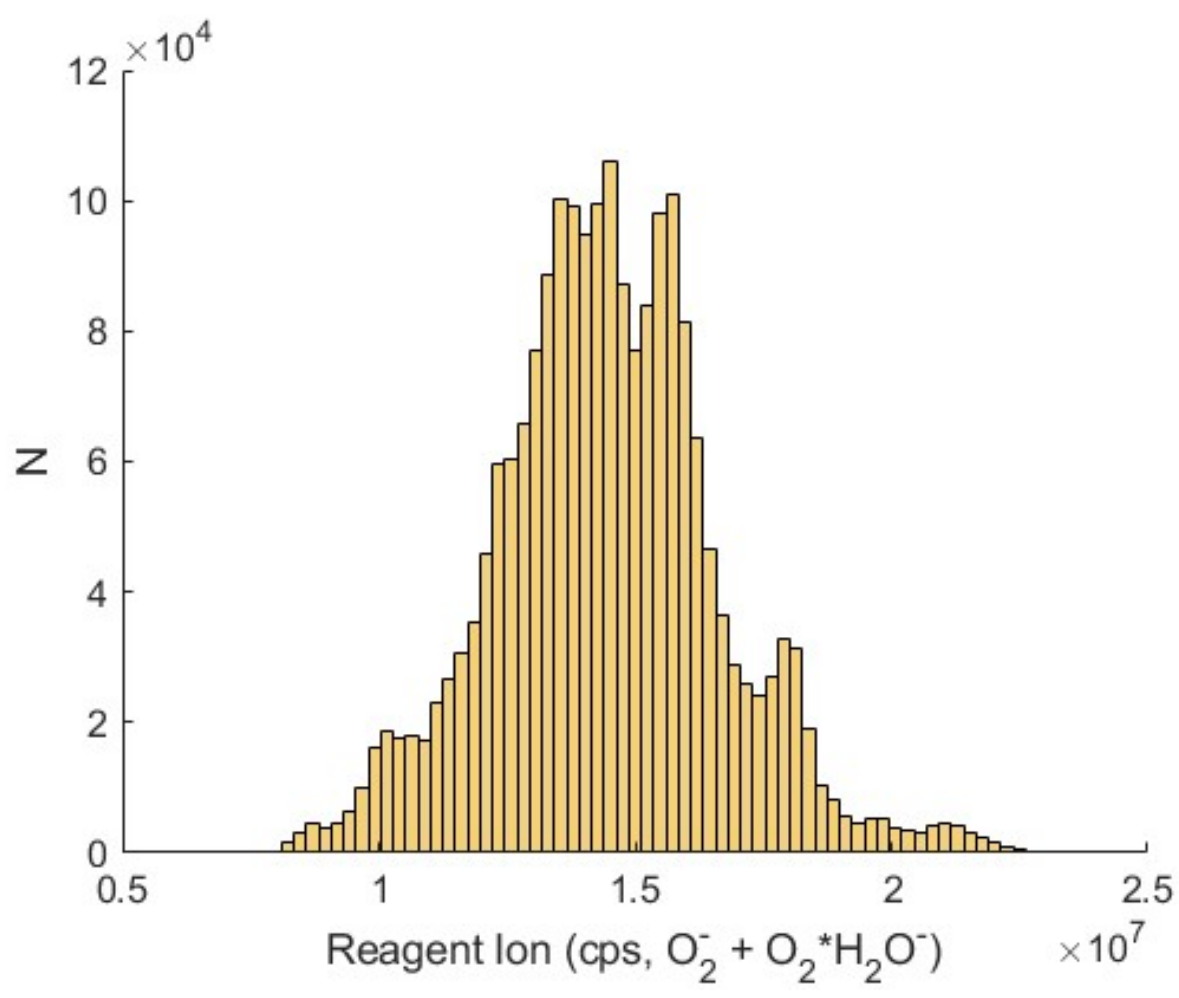

Figure S1: Distribution of $1 \mathrm{~Hz}$ reagent ion signal as the sum of $\mathrm{O}_{2}^{-}$and $\left(\mathrm{O}_{2} \cdot \mathrm{H}_{2} \mathrm{O}\right)^{-}$during the full ambient sampling period from Scripps Pier. Absolute sensitivity to $\mathrm{O}_{3}$ and $\mathrm{NO}_{2}$ scales directly with the magnitude of reagent ion signal. Mean reagent ion signal during the campaign was $1.45 \times 10^{7} \mathrm{cps}$ corresponding to an absolute sensitivity to $\mathrm{O}_{3}$ and $\mathrm{NO}_{2}$ of $1.8 \mathrm{x}$ $10^{5}$ and $1.05 \times 10^{5} \mathrm{cps}^{\mathrm{ppbv}}{ }^{-1}$ respectively at a specific humidity of $8 \mathrm{~g} \mathrm{~kg}^{-1}$. 


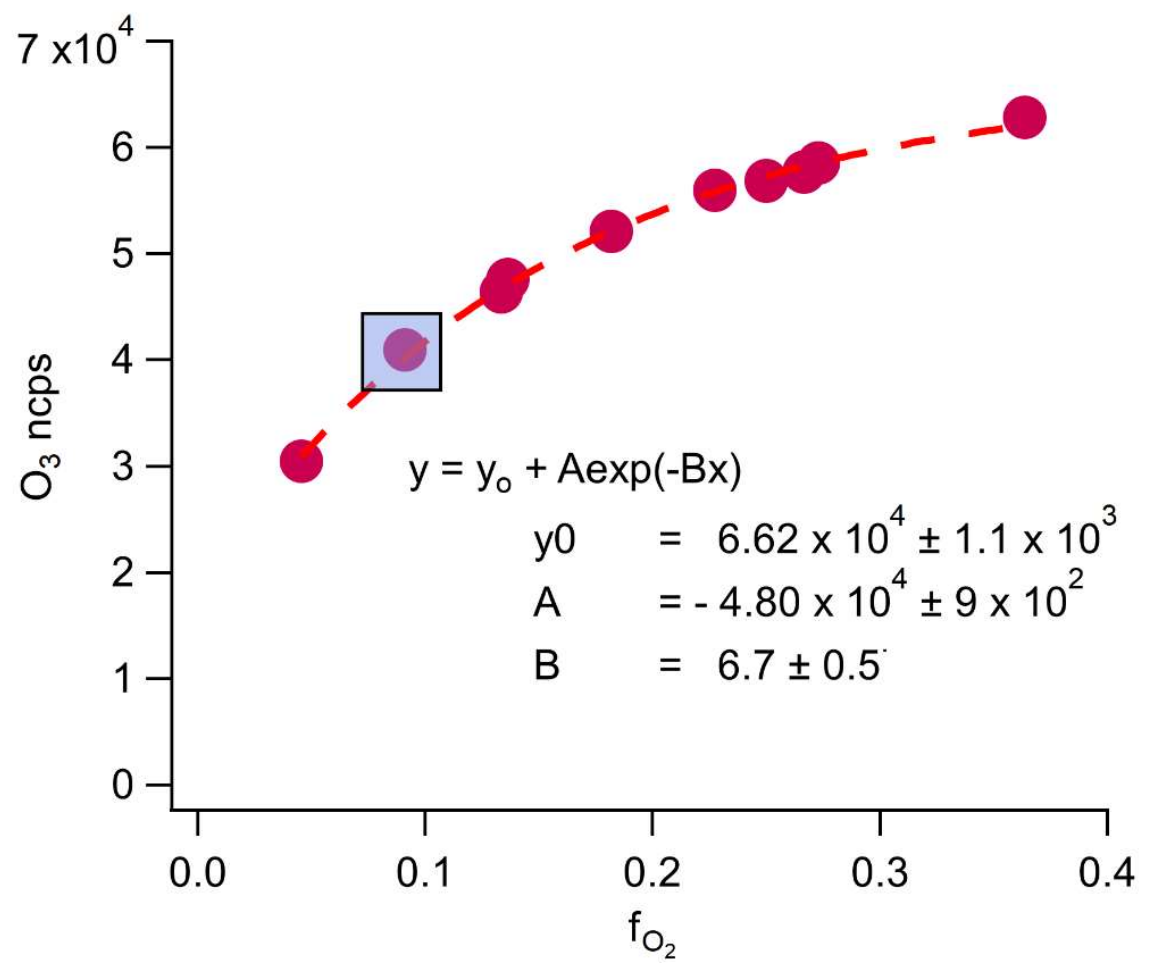

Figure S2: Normalized count rate of background $\mathrm{CO}_{3}^{-}$signal at the sum of $-\mathrm{m} / Q 60$ and $-\mathrm{m} / Q 48$ as a function of oxygen fraction in the reagent ion precursor flow $\left(f_{O_{2}}\right)$, with least squares exponential fit line. Reagent ion flow $f_{O_{2}}$ was varied while the inlet was overflowed with zero air containing $380 \mathrm{ppmv}^{\mathrm{CO}} \mathrm{O}_{2}$, to isolate the background production of $\mathrm{CO}_{3}^{-}$in the reagent ion generation source. The background $\mathrm{O}_{3}$ production was $1.5 \mathrm{ppbv}$ at $\boldsymbol{f}_{\mathrm{O}_{2}}$ of 0.08 (blue square overlay) used during ambient sampling. 

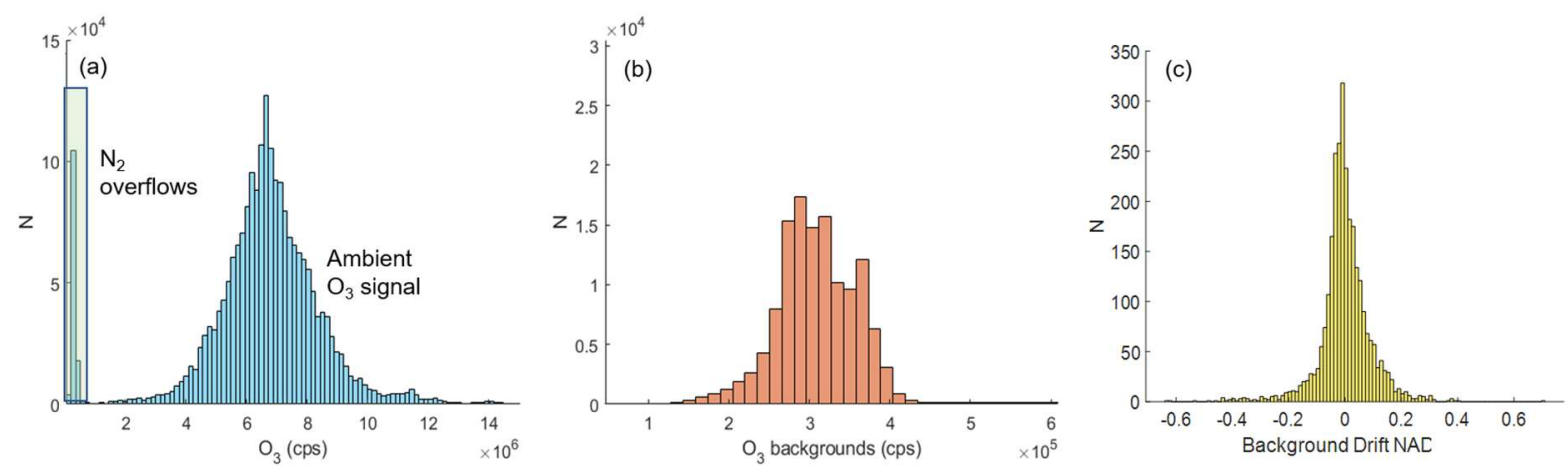

Figure S3: (a) Distribution of observed count rates of the sum of $\mathrm{CO}_{3}^{-}-(-60 \mathrm{~m} / Q)$ and $\mathrm{O}_{3}^{-}(-48 \mathrm{~m} / Q)$ during the full sampling period from Scripps Pier. The green shaded region shows periods of dry UHP $\mathrm{N}_{2}$ overflow of the sampling line. (b) Distribution of observed count rates during dry $\mathbf{N}_{2}$ overflow periods overflow only. Count rates during overflow periods show high consistency between overflow periods with a mean of $3.1 \times 10^{5}$ and standard deviation of $5.0 \times 10^{4}$ counts per second. Residual $\mathrm{CO}_{3}^{-}$during overflow periods is from generation in the reagent ion source rather than off gassing from instrument surfaces. (c) Distribution of normalized adjacent differences of the mean summed $\mathrm{CO}_{3}^{-}$and $\mathrm{O}_{3}^{-}$signal during each three-minute overflow period. The NAD of overflow periods is a measure of point to point stability of the background over the full campaign. The $1 \sigma$ deviation of the NAD distribution is $9 \%$ which gives an upper limit of the variability between subsequent $\mathrm{O}_{3}$ backgrounds. A $9 \%$ variability in the background corresponds to 110 pptv $\mathrm{O}_{3}$ at mean overflow signal of $3.1 \times 10^{5}$ cps. 


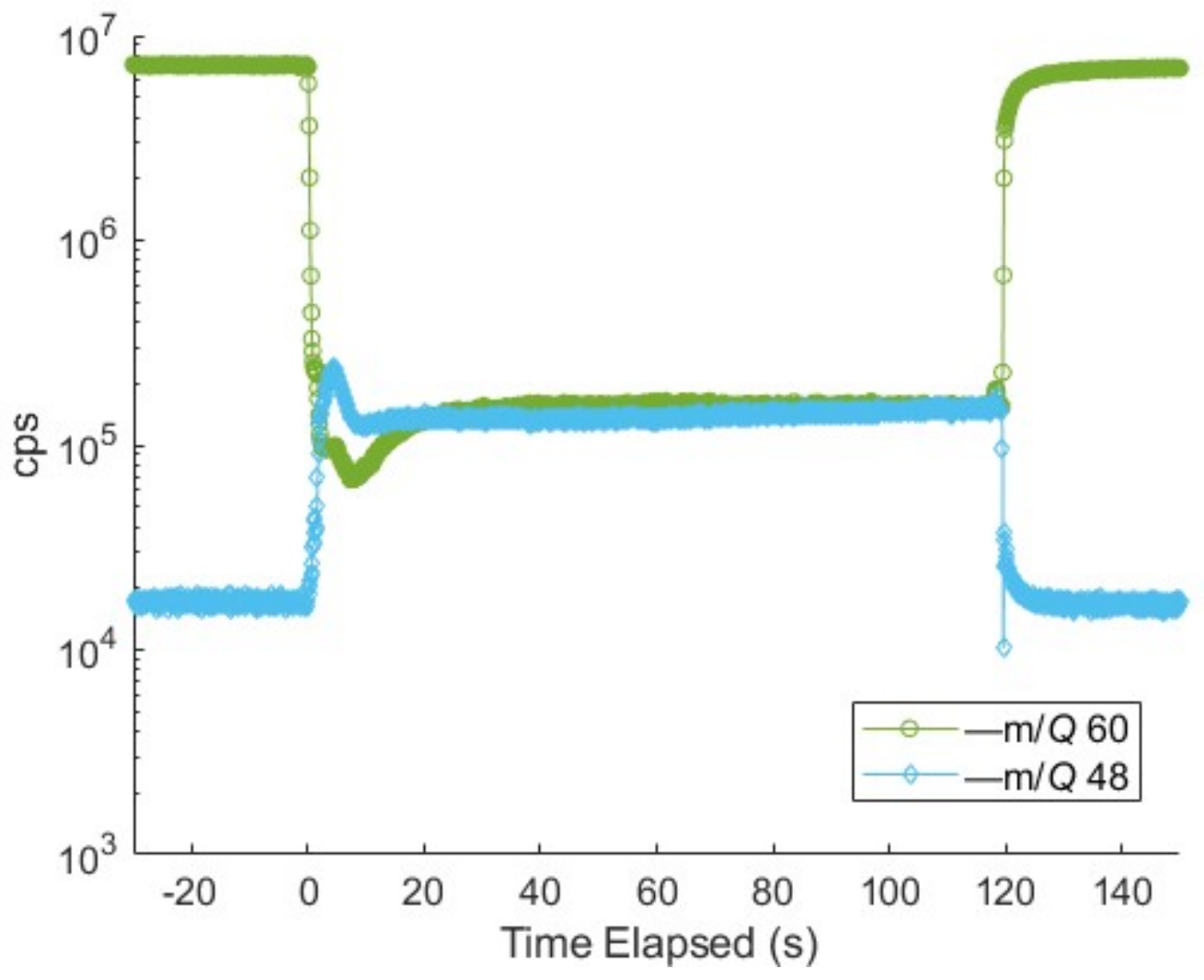

Figure S4: Background count rate of ozone detected as $\mathrm{CO}_{3}^{-}$at $-60 \mathrm{~m} / Q$ and as $\mathrm{O}_{3}^{-}$at $-48 \mathrm{~m} / Q$ during an $\mathrm{N}_{2}$ overflow background determination period during ambient sampling at Scripps Pier. Overflow of dry $\mathrm{N}_{2}$ was started at $0 \mathrm{~s}$ and stopped at $120 \mathrm{~s}$. During $\mathrm{N}_{2}$ overflow periods during field sampling, no $\mathrm{CO}_{2}$ was added to drive the reaction product to $\mathrm{CO}_{3}^{-}$. This leads to the detection of a portion of the $\mathrm{O}_{3}$ background signal as $\mathrm{O}_{3}^{-}$during $\mathrm{N}_{2}$ overflow which must be accounted for. Count rates of $\mathrm{O}_{3}^{-}$were of similar magnitude to the $\mathrm{CO}_{3}^{-}$signal during $\mathrm{N}_{2}$ overflow periods during field sampling. From lab calibrations the sensitivity to $\mathrm{O}_{3}^{-}$at $0 \mathrm{ppmv} \mathrm{CO}_{2}$ and $0 \mathrm{~g} \mathrm{~kg}^{-1} \mathrm{SH}$ is approximately a factor of three higher than $\mathrm{CO}_{3}^{-}$. Accounting for the background signal at $\mathrm{O}_{3}^{-}$increases the mean $\mathrm{O}_{3}$ background during field sampling by $0.6 \mathrm{ppbv}$ (from approximately 0.7 to a $1.3 \mathrm{ppbv}$ total $\mathrm{O}_{3}$ background). 


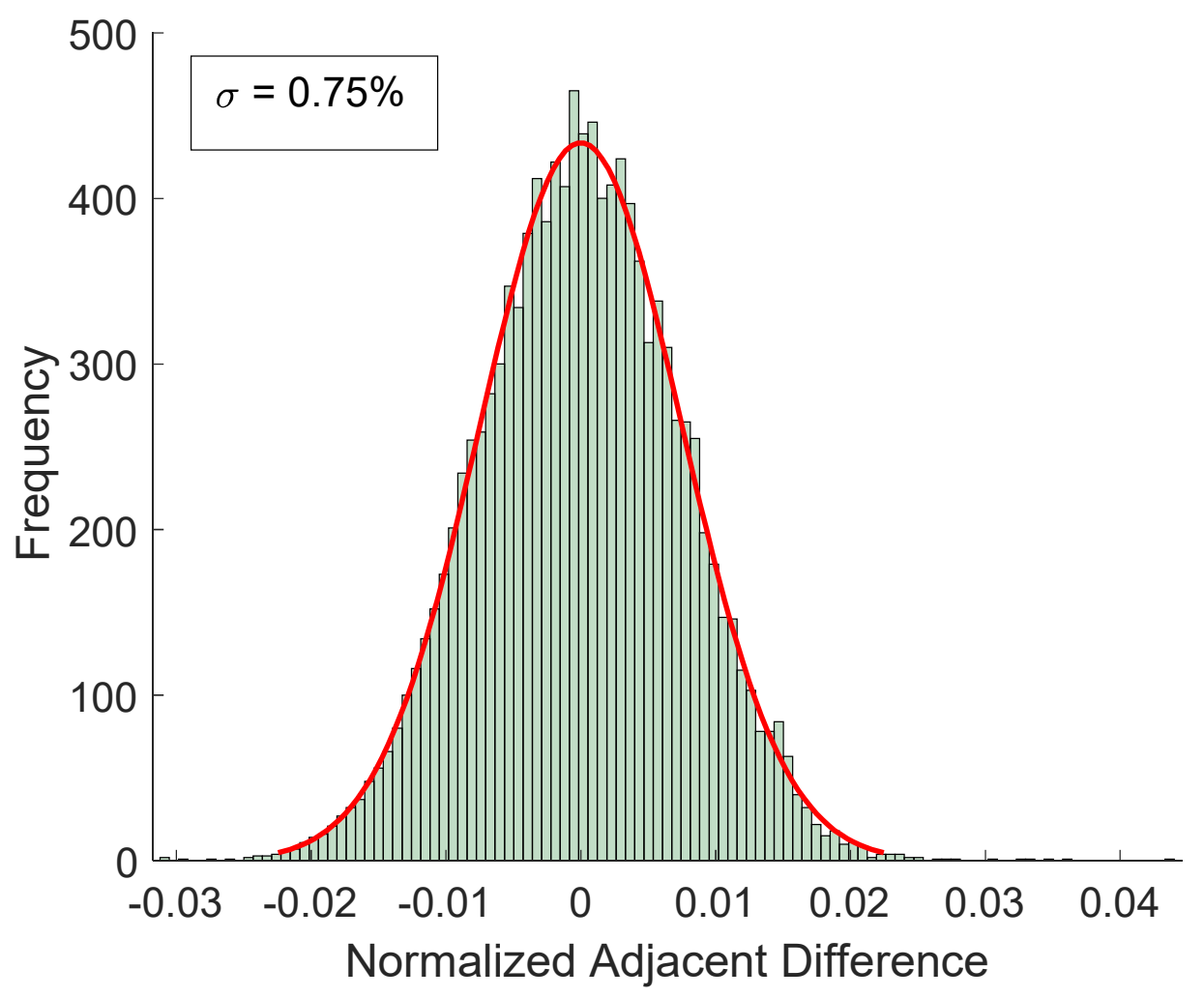

Figure S5: Distribution of normalized adjacent differences of $10 \mathrm{~Hz} \mathrm{O}_{3}$ signal during a 2-minute dry $\mathrm{N}_{2}$ overflow period during ambient sampling at Scripps Pier. The $1 \sigma$ upper limit of precision is $0.75 \%$ corresponding to 7.5 pptv precision in the 1.3 ppbv background $\mathrm{O}_{3}$ signal. Precision limitations from background $\mathrm{O}_{3}$ generation in the ion source are unlikely to be significant in the overall precision of the instrument during ambient sampling where precision is 300 pptv at 40 ppbv ambient $\mathrm{O}_{3}$ concentrations. 

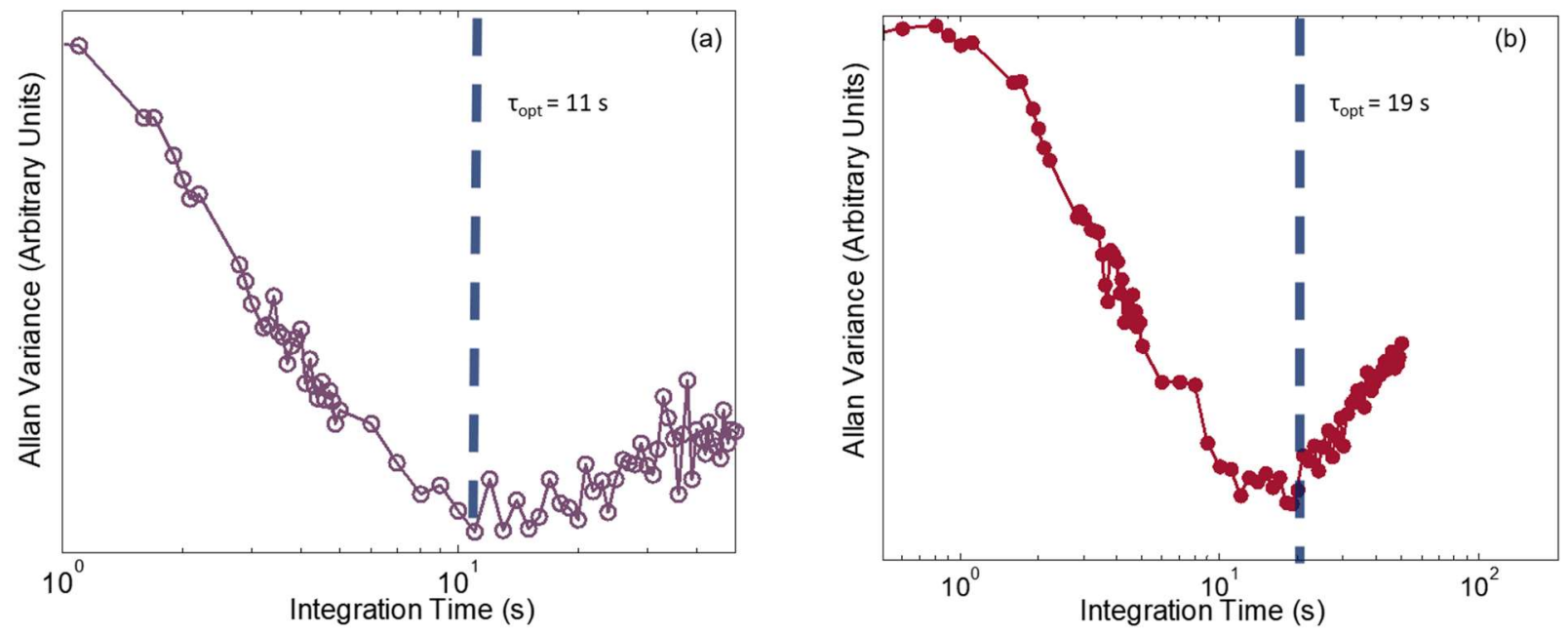

Figure S6: Allan variance determination of optimal averaging time for (a) $\mathrm{O}_{3}$ and (b) $\mathrm{NO}_{2}$ for sampling of a constant calibration source in lab for approximately 10 minutes with $10 \mathrm{~Hz}$ data collection. The minimum of the Allan variance curve is the optimum averaging time $\left(\tau_{o p t}\right)$ that results in the lowest achievable LOD. For $\mathrm{O}_{3} \tau_{\text {opt }}$ was $11 \mathrm{~s}$, and for NO $\tau_{\text {opt }}$ was $19 \mathrm{~s}$. 


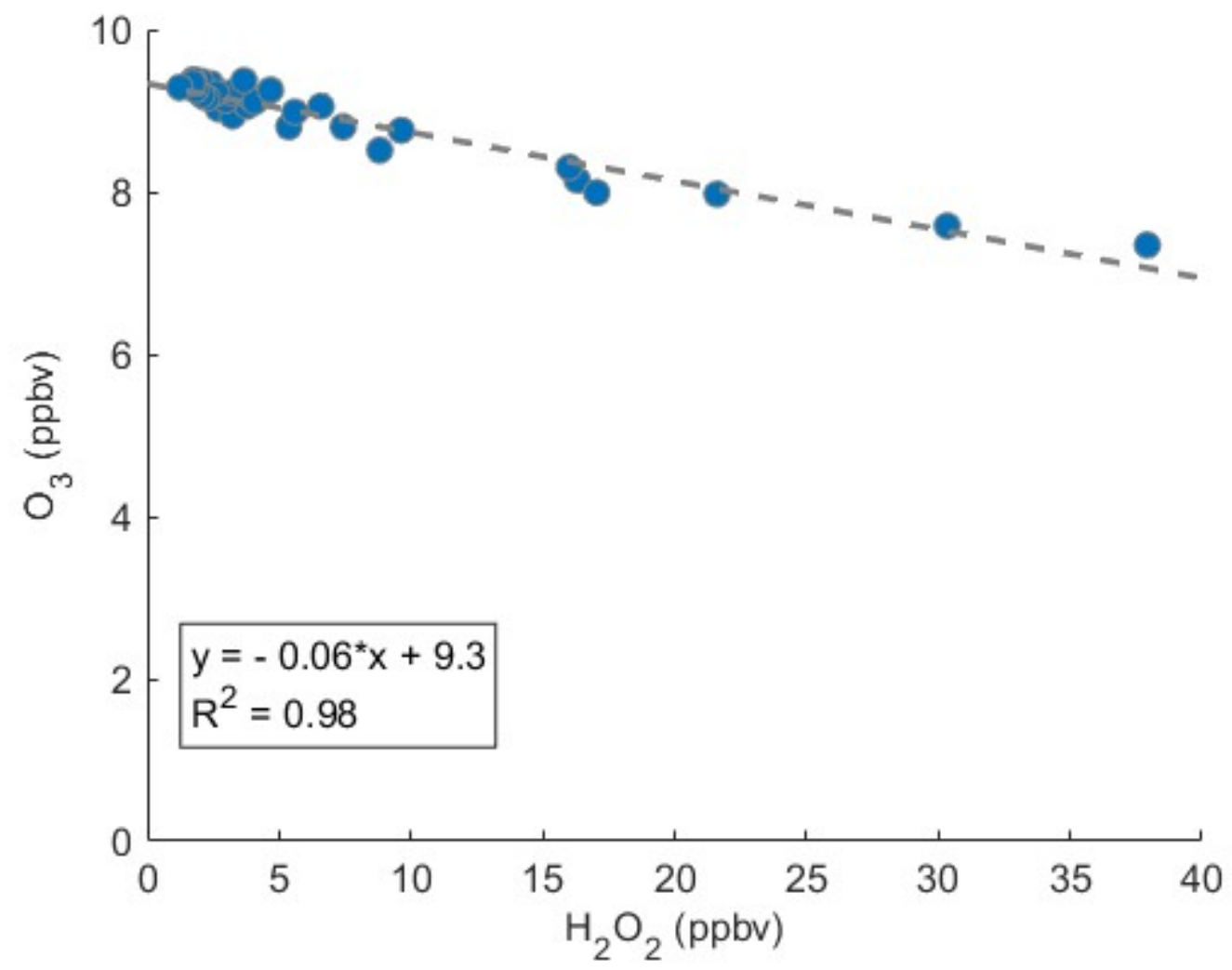

Figure S7: Regression of $\mathrm{O}_{3}$ signal against $\mathrm{H}_{2} \mathrm{O}_{2}$ from laboratory sampling of approximately 8 ppbv $\mathrm{O}_{3}$ with fast introduction of a $\mathrm{H}_{2} \mathrm{O}_{2}$ source up to $40 \mathrm{ppb}$. Linear regression shows a loss of $0.06 \mathrm{ppbv}$ of the $\mathrm{O}_{3}$ signal per ppbv $\mathrm{H}_{2} \mathrm{O}_{2}$ added. $\mathrm{H}_{2} \mathrm{O}_{2}$ is detected as an adduct with $\mathrm{O}_{2}^{-}$the parent ion $\mathrm{H}_{2} \mathrm{O}_{2}^{-}$at $-\mathrm{m} / Q 66$. The $\mathrm{CO}_{3}\left(\mathrm{H}_{2} \mathrm{O}_{2}\right)^{-}$adduct at $-94 \mathrm{~m} / Q$ is observed respond with increase with $\mathrm{H}_{2} \mathrm{O}_{2}$ introduction but has a persistent high signal which is attributed to a ubiquitous $\mathrm{O}_{2}\left(\mathrm{CO}_{2}\right)\left(\mathrm{H}_{2} \mathrm{O}\right)^{-}$adduct. 


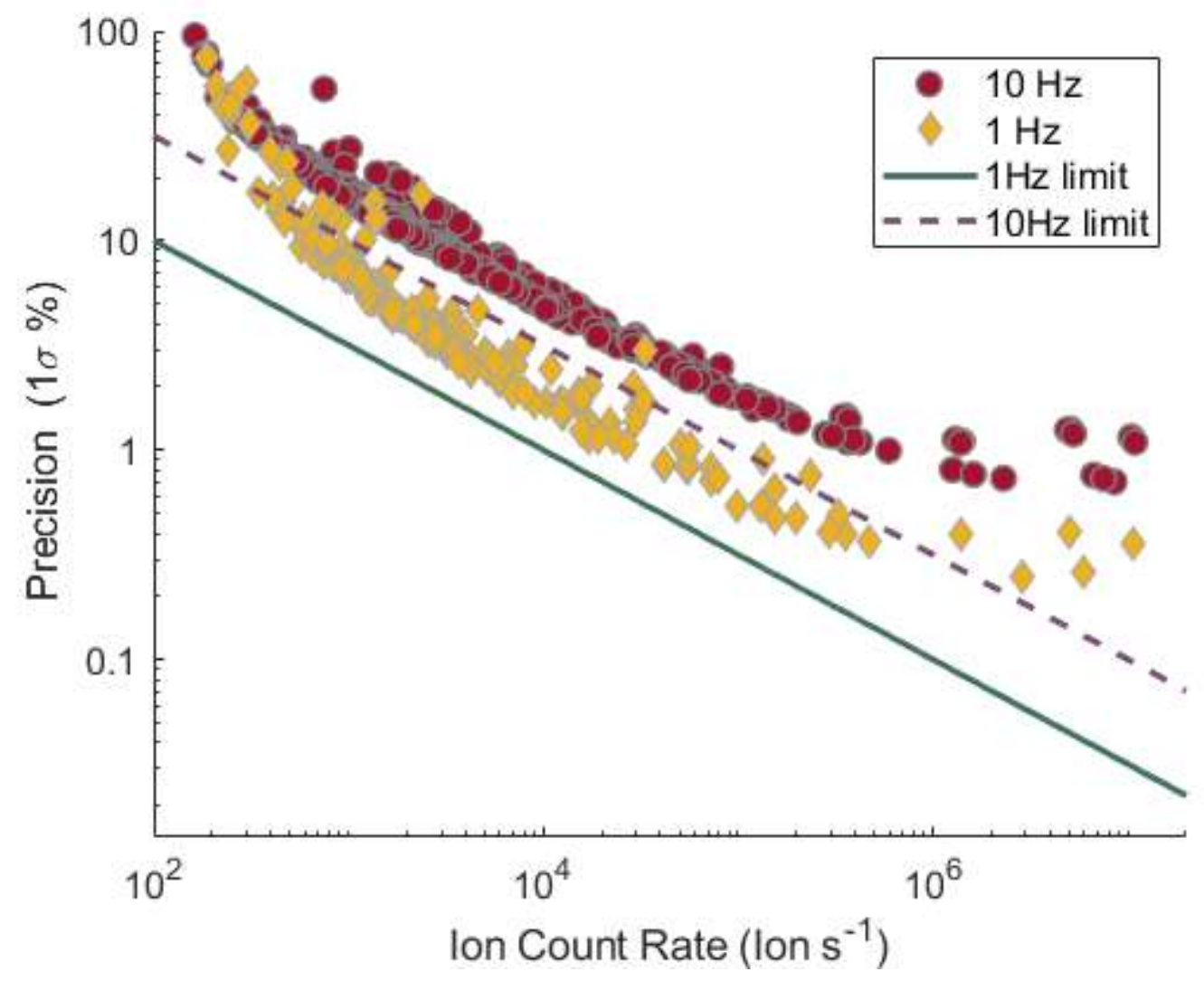

Figure S8: Short-term instrument precision from distribution of normalized adjacent differences against ion count rate for $10 \mathrm{~Hz}$ and $1 \mathrm{~Hz}$ data averaging. Normalized adjacent differences were calculated for all masses $-\mathbf{3 0}$ to $-250 \mathrm{~m} / Q$ for a $27-$ minute ambient sampling period. Precision is reported as $1 \sigma$ of the NAD distribution for each mass. Ion count rates are the mean unnormalized count rate over the 27 -minute sampling period. 


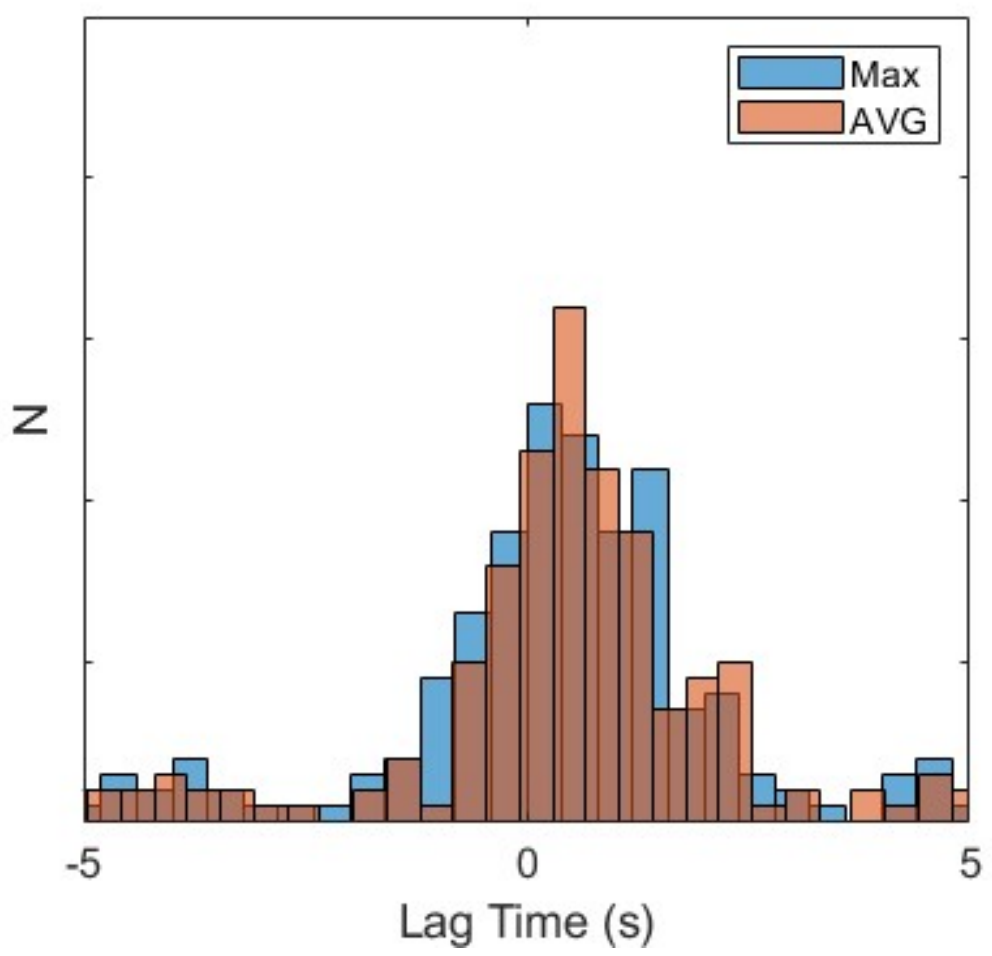

Figure 59: Histogram of determined lag times determined as the maximum (MAX) absolute magnitude of the autocovariance and from the maximum absolute magnitude of a 10 point moving median (AVG) of the autocovariance over a \pm 5 s lag window. 


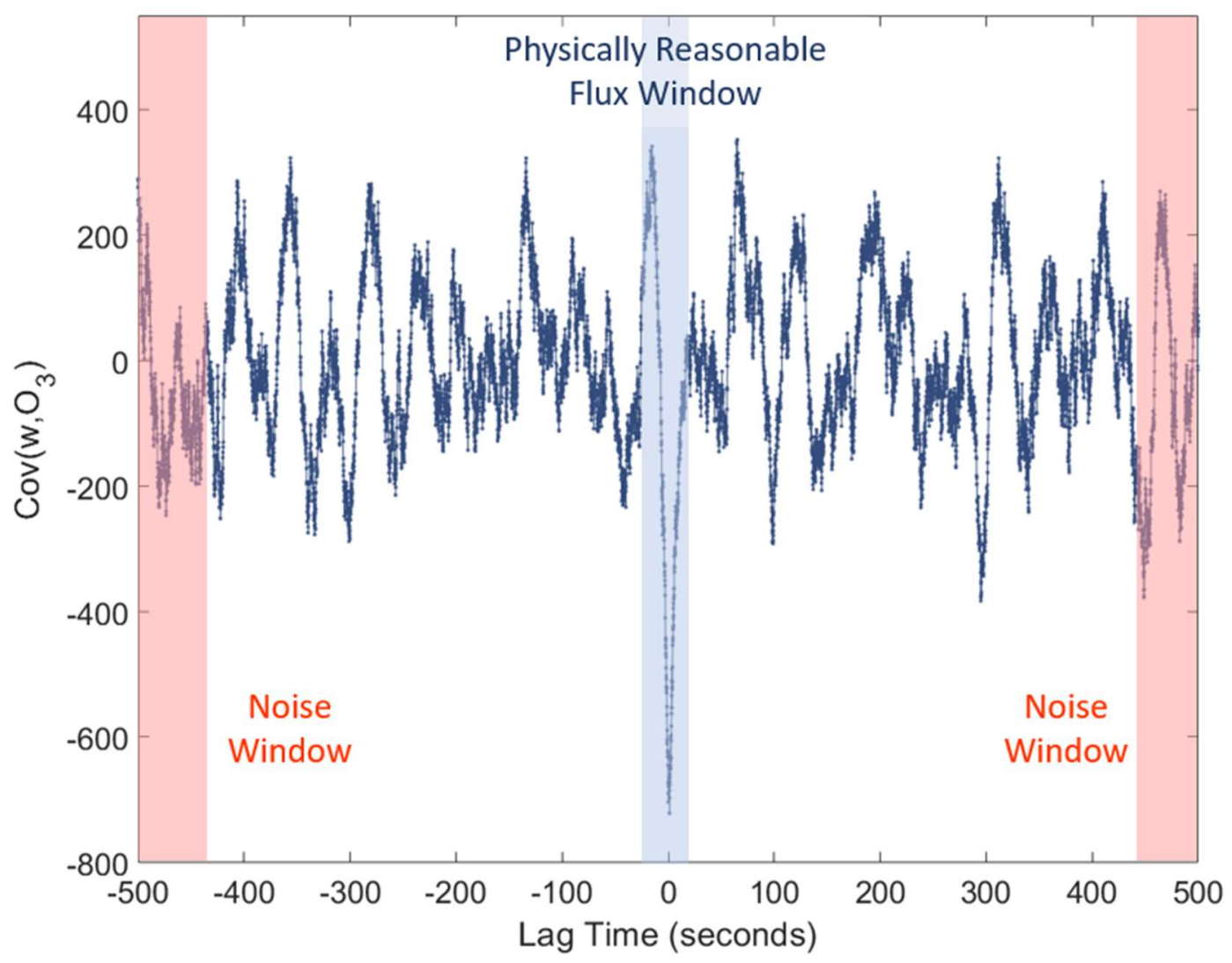

Figure S10: Calculation of cross-covariance at very long lag times $(-500$ to $-485 \& 485-500$ s) used to determine the flux LOD via the LODRMS and LODo methods. Covariance in the physically reasonable flux window of lag times (-3 to $3 \mathrm{~s})$ is well resolved from the covariance magnitude at long lag times driven by noise. 


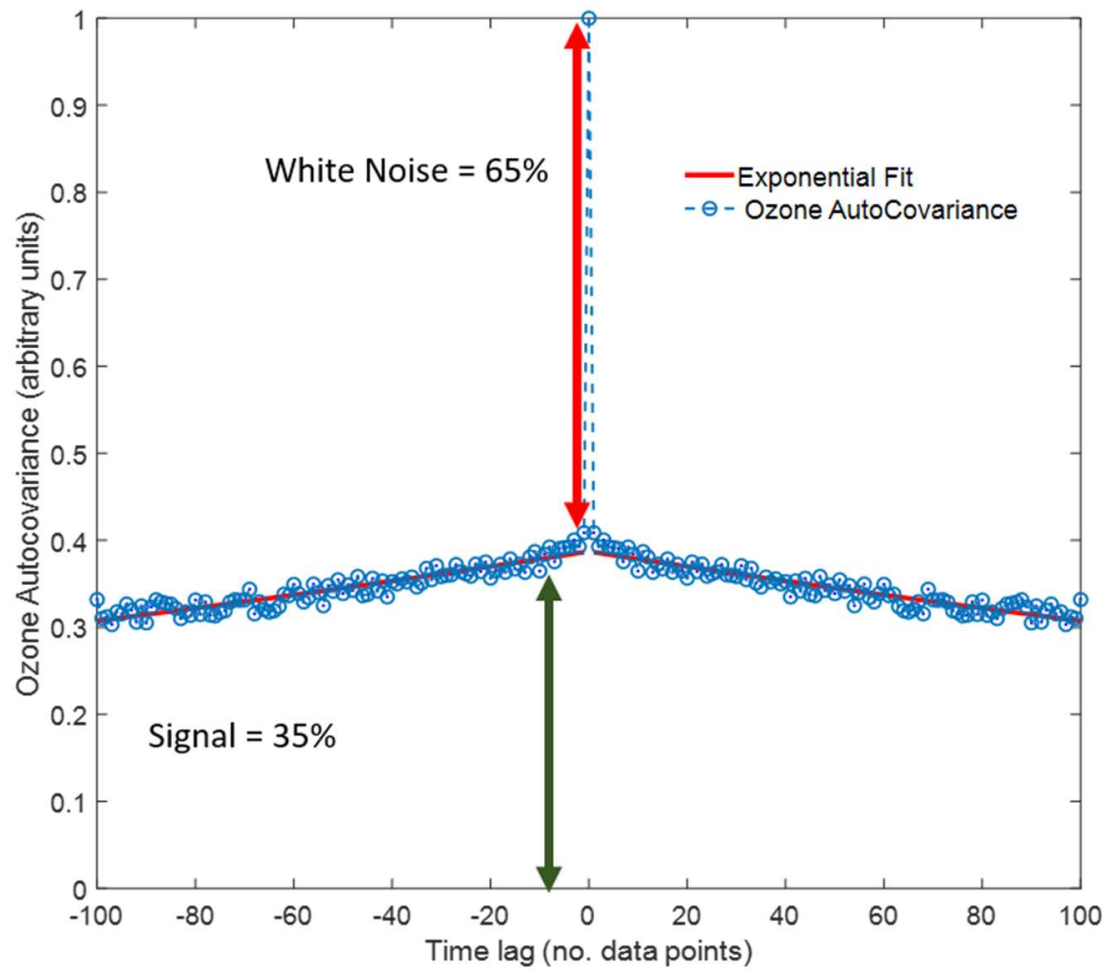

Figure S11: Ozone auto-covariance for $10 \mathrm{~Hz} \mathrm{O}_{3}$ signal for a single flux averaging period. White noise only contributes to the auto-covariance at a lag of 0 points. Auto-covariance at other lag times is from real long-term coherence in the signal, either from atmospheric variability or instrument drift. 


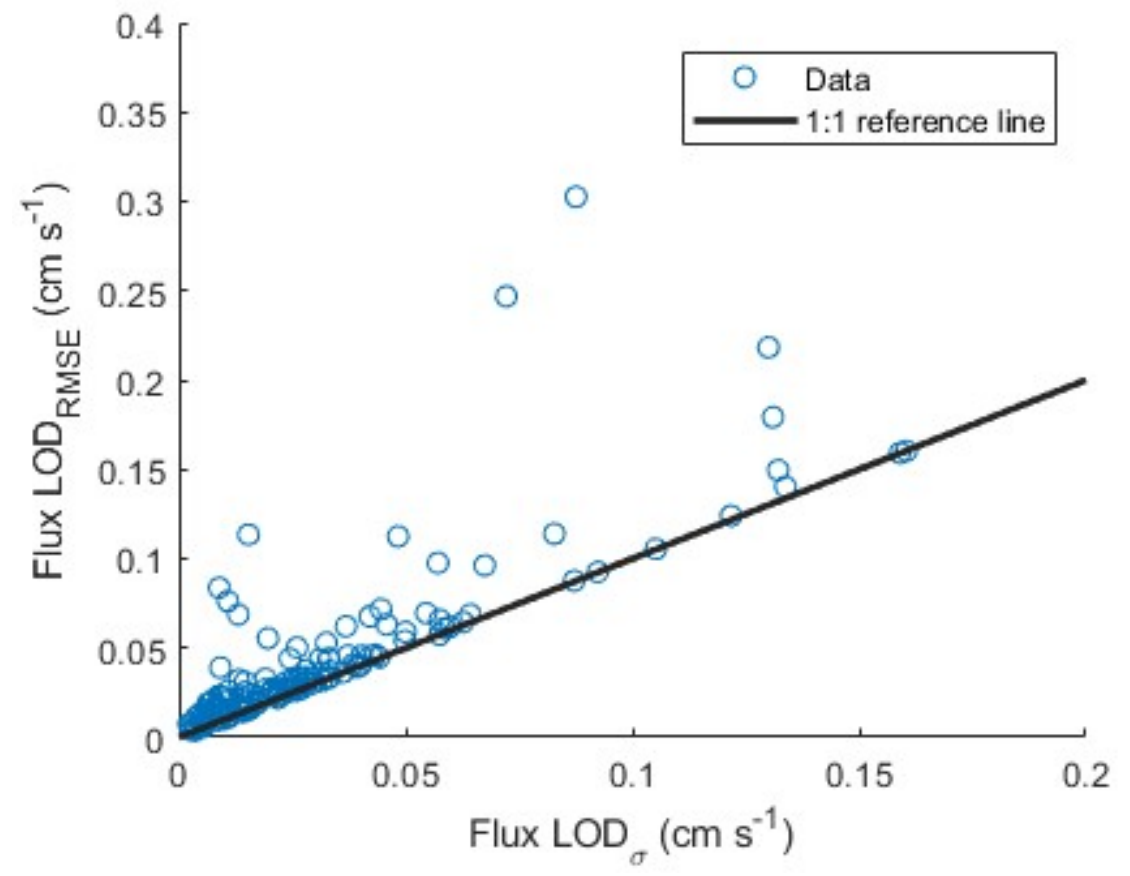

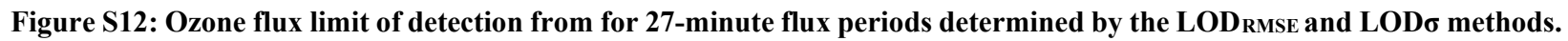

\section{References}

Brophy, P. and Farmer, D. K.: Clustering, methodology, and mechanistic insights into acetate chemical ionization using high-resolution time-of-flight mass spectrometry, Atmos. Meas. Tech., 9(8), 3969-3986, doi:10.5194/amt-9-3969-2016, 2016. 